\title{
Enfermagem como prática social: um exercício de reflexão
}

\author{
Nursing as social practice: an exercise of reflection
}

Enfermería como una práctica social: un ejercicio de reflexión

\author{
Maria Cristina A. Figueiredo Trezza', Regina Maria dos Santos', Joséte Luzia Leite \\ 'Universidade Federal de Alagoas. Departamento de Enfermagem. Maceió, AL \\ "Universidade do Rio de laneiro. Rio de Janeiro, RJ
}

Submissão: 18/10/2007

Aprovação: 04/10/2008

\section{RESUMO}

Neste trabalho propomos refletir sobre a enfermagem entendida como uma prática social. Para construir essas idéias, revisitamos esse conceito nas suas raízes filosóficas e sociais. Com o intuito de contribuir para esta reflexão, buscamos, no desenvolvimento da enfermagem, desde os seus primórdios, características que a definem como uma prática histórica e socialmente construída. Por fim propomos também um conceito de prática social e, nesta perspectiva, construímos, ao longo do texto, um outro conceito para enfermagem.

Descritores: Enfermagem; Enfermagem prática; Filosofia em enfermagem.

\section{ABSTRACT}

In this work we aimed at reflecting about the nursing as a social practice. To build these ideas, we reconsidered this concept in its philosophical and social roots. With the purpose to contribute for this reflection, we looked for the characteristics that define the nursing as an historical and socially build practice, through the nursing development, since its beginning. At last we also propose a concept of social practice and, into this perspective, we built,along the text, an other concept for the nursing.

Descriptors: Nursing; Nursing, practical; Philosophy, nursing.

\section{RESUMEN}

La propuesta de este trabajo es reflexionar sobre la enfermería comprendida como una práctica social. Para construirlo hemos buscado ese concepto en sus raíces filosóficas y sociales. Intentando contribuir para esta reflexión, presentamos un análisis del desarrollo de enfermería, desde el comienzo de su práctica histórica y socialmente construida. Al fin, proponemos un concepto de práctica social, construyendo, a lo largo del texto un otro concepto para Enfermería.

Descriptores: Enfermería; Enfermería práctica; Filosofía en enfermería. 


\section{CONSIDERAÇÕES INICIAIS}

O objeto deste trabalho é a enfermagem entendida como prática social, decorrendo daí a pretensão de refletir acerca do significado desta expressão e de seu reconhecimento no âmbito do mundo do trabalho e da enfermagem como tal. No exercício desta reflexão naturalmente será necessário reportarmo-nos à evolução desta prática social em particular Que é a Enfermagem, tentando reconhecê-la no bojo das práticas sociais vigentes nas primeiras formações sociais e o processo pelo Qual se firmou como profissão.

Para nos posicionarmos sobre esta forma de compreender a Enfermagem, sentimos necessidade de buscar um melhor entendimento desses termos nas ciências sociais e na própria filosofia, para então proceder a uma discussão do Que inicialmente estamos a chamar de Enfermagem como prática social.

\section{DISCUTINDO A EXPRESSÃO "PRÁTICA SOCIAL"}

Nas discussões que desenvolvemos para definir o Que de fato seria este trabalho, percebemos as dificuldades Que contornam o entendimento da enfermagem como prática social, por razões ligadas a alguns fatores entre os Quais estão os de natureza filosófica e histórica. Pensamos mesmo Que a percepção da existência dessas dificuldades seria uma das razões Que nos levaram a elaborá-lo. Optamos, então, por iniciar esta etapa definindo a expressão Prática Social pelos seus termos em separado para depois tentar dar sentido ao seu conjunto. Sentimos ainda a necessidade de definir evolução porque é a perspectiva sob a Qual pretendemos elaborar as nossas reflexões.

Assim, temos Que, segundo Ferreira(1), Evolução significa desenvolvimento progressivo duma idéia, acontecimento, ação, entre outros. Abbagnano ${ }^{(2)}$, acrescenta Que a palavra conserva ainda, o sentido genérico de desenvolvimento, mas, mais freqüentemente, é usada para designar uma doutrina particular que se chama teoria da evolução. Ora, por essa expressão podem-se entender duas coisas diferentes: $I^{\mathrm{a}}$. Teoria biológica da transformação das espécies vivas umas nas outras; $2^{\text {a }}$. Teoria metafísica do desenvolvimento progressivo do universo na sua totalidade (Que é uma hipótese) admitida ou pressuposta por muitas doutrinas filosóficas modernas e contemporâneas.

Silva ${ }^{(3)}$, concordando em princípio com Abbagnano, esclarece Que a essência do significado do termo evolução é a de desenrolar, desenvolver, ou desdobrar, designando assim, movimento de natureza metódica, Que gera novas espécies de mudanças. Mais especificamente, designa o processo de mudança através do Qual algo novo é produzido de tal modo contínuo, Que a identidade ou a individualidade do objeto original não seja violada.

Ao conceituar a palavra evolução desta maneira, é o momento de aproxima-la do fenômeno "sociedade", na perspectiva de Qualificar a evolução a Que estamos nos referindo. Assim especificado, pode-se entender, segundo Ferreira ${ }^{(1)}$, Que a expressão Evolução Social refere-se ao processo de desenvolvimento de uma determinada sociedade, das suas formas e instituições, ou das suas funções culturais.

Prática, segundo Ferreira ${ }^{(1)}$, deriva do grego, praktikós e Quer dizer 'capaz de agir'. Japiassu, Marcondes ${ }^{(4)}$, estabelece Que prática diz respeito à ação. Ação Que o homem exerce sobre as coisas, aplicação de um conhecimento em uma ação concreta, efetiva. Opõe-se ao teórico especulativo. Nesta mesma linha, Abbagnano ${ }^{(2)}$, define prática, em geral, como aquilo Que é ação ou concerne à ação. Para este autor, há três significados diversos: a) $\mathrm{O}$ Que dirige a ação; b) $\mathrm{O}$ Que se pode transformar em ação; c) $\mathrm{O}$ Que é racional na ação.

O primeiro significado é o filosófico tradicional; (Platão, Aristóteles). O segundo significado, Que pertence à linguagem comum mais do Que à filosófica, ensina Que prática é o Que é fácil ou imediatamente transformável em ação. O terceiro significado é o mais restrito e foi empregado por Kant Que entende por prática, tudo aquilo que é possível por meio da liberdade.

No que se refere ao termo social, Ferreira ${ }^{(1)}$ o define como sendo "da sociedade ou relativo a ela", "sociável", "Que interessa à sociedade". Conforme Abbagnano ${ }^{(2)}$, social é o Que pertence à sociedade, ou tem em vista suas "ações sociais", "movimentos sociais", "Questões sociais". Que diz respeito à análise ou ao estudo da sociedade. Para Silva(3), social se refere a Qualquer tipo de comportamento ou atitude, influenciado (direta ou indiretamente) pela experiência passada ou presente do comportamento de outras pessoas, ou orientado (consciente ou inconsciente) para outras pessoas.

Encontramos alguns autores, nos dicionários de ciências sociais, Que já passam a explicar esses termos na sua conotação de "prática social”. Deixam claro Que a mesma tem estreita relação com os princípios do materialismo histórico dialético ao explicitar as condições objetivas da existência e as relações do ser humano no mundo do trabalho.

Silva ${ }^{(3)}$, ao citar Marx, diz que da simples prática de conquista da natureza, os homens passam a uma prática social mais completa, onde sua atividade produtiva engendra determinadas relações de produção, o Que constitui o eixo do processo do conhecimento. Explica ainda Que a prática social do homem em torno de sua atividade produtiva inaugura outras atividades humanas, como as artísticas, as políticas, as científicas, etc., Que integram o conhecimento humano.

Althusser $^{(5)}$ entende por prática, todo o processo de transformação de uma dada matéria prima em um produto determinado, transformação efetuada por um trabalho humano determinado, utilizando meios de produção determinados. O momento capital de toda prática é o Que articula os agentes, os meios e a técnica de produção. A prática ligada à atividade material não é exclusiva; a prática social pressupõe a luta de classes, transformando a consciência do homem. Pode-se então relacionar a expressão prática social ao desenvolvimento de uma atividade por e para pessoas, para atender a uma necessidade sentida por essas pessoas (entendidas aQui como "ser social").

Sendo assim, é preciso ter cuidado para não deixar escapar o sentido de humanidade Que existe na expressão "prática social" e Que tentamos ressaltar em nossas colocações. Isso Quer dizer Que é na humanidade das relações entre os homens, na produção da sua sobrevivência Que as práticas sociais acontecem. Mas, como ensinam, Lobo Neto et $\mathrm{al}^{(6)}$, a prática social não pode ser vista, simplesmente, como uma atividade Que se manifesta como fenômeno ou fato, mas todo um conjunto de atividades humanas Que se diferenciam de QualQuer comportamento natural.

Nesta condição, é possível dizer Que a prática social está inserida 
no processo cultural, produzido históricamente, ou seja, é produzida da relação de interação intencional entre os seres humanos e na relação de homens e mulheres com a natureza, com o mundo das coisas ${ }^{(6)}$.

Em outras palavras e, de posse dessas várias explicações, passamos a propor Que prática social seja entendida como a ação Que se desenvolve em resposta a um interesse e/ou necessidade da pessoa e da sociedade, exercida por seus praticantes sobre o objeto do seu fazer, através da Qual estabelecem relações, aplicam o seu saber como forma de transformar uma realidade concreta. Esses praticantes, ao participar desse processo de transformação, transformam-se também. É nesta perspectiva, Que discutiremos a Enfermagem como prática social.

\section{ENFERMAGEM COMO PRÁTICA SOCIAL - UM POUCO DO PASSADO}

Desde as primeiras organizações humanas era reconhecida a necessidade de cuidar para preservar a vida e protelar a morte. $\mathrm{O}$ exercício destas atividades esteve ao encargo das mulheres, diferentemente da tarefa de suturar os feridos, combater e caçar, tarefa de homens, como relata Colliere ${ }^{(7)}$. Acompanhando o desenvolvimento dos grupos sociais a prática de cuidar foi se transformando em ofício, exercido por algumas mulheres Que detinham conhecimentos sobre o funcionamento do corpo, sobre o processo de parir, amamentar e sobre os efeitos das ervas, entre outros. Em troca dos seus serviços, recebiam o necessário para sua sobrevivência e reposição de suas mezinhas. Preocupavam-se em transmitir seus conhecimentos a outras mulheres e neste mister, sedimentaram seus saberes sem contudo os documentar ${ }^{(7-11)}$.

Se aproximarmos esta descrição do processo de prestar cuidado às pessoas do conceito Que formulamos de "Prática Social", veremos que ali se enquadra, o Que nos leva a identificar aí os prenúncios da enfermagem, nascendo já como prática social, ainda não científica, mas independente e confiante nos seus conhecimentos e nos resultados positivos de suas ações.

Mais tarde, em torno do Século X, essas mesmas mulheres, consideradas sábias pelo povo, mas bruxas pela Igreja ${ }^{(8,10)}$, foram alijadas de seus fazeres, condenadas a abandonarem os seus saberes Que foram apropriados pelos homens Que se debruçaram sobre métodos e técnicas de curar. Curiosamente, junto com este desaparecimento, tornaram-se escassas as referências sobre o desenvolvimento da Enfermagem ou o trabalho das mulheres enfermeiras. Não obstante, persistindo a necessidade social de cuidados (de enfermagem), Pires ${ }^{(1)}$ esclarece que os conhecimentos e teorias em relação ao processo saúde/doença até então desenvolvidos - incluindo os produzidos pelas mulheres e transmitidos pela tradição oral - foram guardados pela Igreja, nos mosteiros e reorientados para respeitar os princípios e limitações impostas pelo cristianismo.

Assim, como relata a autora, havia o atendimento aos membros das classes elevadas, praticado pelos físicos (médicos, conforme explica Pires ${ }^{(1)}$, e o cuidado dirigido aos pobres era feito em parte pelos religiosos ...e pelos práticos, pelos homens de ofício e pelas parteiras juntamente com as mulheres Que dominavam conhecimentos especiais e cuidavam de doentes. Essas, parteiras e práticas, tiveram mais tarde o seu trabalho incorporado à profissão de enfermagem ${ }^{(1)}$.

O processo de mudança do feudalismo para o capitalismo traz modificações no atendimento às pessoas, retirando este trabalho do seu local habitual Que era o domicílio, trazendo-o para os hospitais. Aí o trabalho de assistência, muito embora executado por diversos "profissionais" - Que dominavam a íntegra do seu fazer - era subordinado ao médico, detentor do conhecimento teórico, jamais envolvido com as atividades manuais ${ }^{(11,12)}$.

É interessante verificar como esta lógica ainda está presente em nossos dias. Parece Que todo o avanço registrado até o momento está veiculado ao aprimoramento de instrumentos de trabalho principalmente equipamento e instrumental e aos mecanismos de controle e supervisão - gerência - do processo de trabalho. Em sendo um trabalho socialmente necessário, continuava naQuele período guardando as características Que o Qualificavam como uma prática social.

Na primeira metade do Século XIX as mulheres enfermeiras estavam distribuídas em dois espaços distintos: o primeiro poderia ser descrito como aQuele que se reorganizava nos hospitais do início do capitalismo, exercendo sua prática em péssimas condições, distante do conhecimento e do respeito Que haviam acumulado nos primórdios da civilização. O segundo era o mundo religioso, onde trabalhavam em situação de submissão, dentro das Instituições Religiosas, como ajudantes daQueles Que curavam enfermos ${ }^{(10-12)}$. Houve na segunda metade desse século, um movimento de resgate o trabalho desenvolvido pelas enfermeiras, liderado por Florence Nightingale.

Nesta fase a Enfermagem passa por uma fase de "redefinição" onde sua prática passa a ser descrita como "ciência, arte, ideal". Nesta nova performance, dedicavam-se a cuidar dos doentes institucionalizados, muito embora as mulheres enfermeiras não tivessem abandonado totalmente a prática do cuidado domiciliar ${ }^{(10-}$ ${ }^{12)}$. Florence Nightingale ${ }^{(13)}$, na medida de suas possibilidades tentou estabelecer um novo estatuto para a Enfermagem, sendo altamente favorável à lógica econômica Que se instalava. Poderíamos especular Que ao se categorizar como IDEAL alia o trabalho ao ideal cristão de servir sem recompensas materiais; ao se colocar como ARTE, encontra o caminho para o desenvolvimento de técnicas Que, associada aos princípios científicos constituíam o seu saber específico (CIÊNCIA) $)^{(13)}$. Sobre esta nova explicação para o Que é enfermagem poderíamos ainda argumentar Que ao defini-la como Ciência, Arte e Ideal, foi possível coloca-la no patamar das profissões, reconeuistar saberes Que lhe tinham sido expropriados e assegurar-lhe respeito e credibilidade.

Por outro lado, ao assim compreender a enfermagem, nos parece Que houve a vontade de excluí-la do Que Marx considerava como Trabalho Improdutivo ${ }^{(14)}$ e Que dizia respeito aos serviços prestados às pessoas para garantir-lhes a sobrevivência: o trabalho doméstico, a educação, o cuidado com as crianças, com os velhos e os doentes $^{(14)}$.

Sendo vista como Arte e Ciência, a enfermagem parece não se ver como trabalho, como "prática social", mesmo Que continue guardando aquele princípio de atividade exercida por pessoas, para pessoas, de acordo com suas necessidades (destaque nosso). Não nos parece ter sido esta a intenção de Miss Nightingale, pois ao organizar a prática de enfermagem, ao dividir o seu fazer conforme a classe social das mulheres enfermeiras, ao sistematizar o ensino, 
garantiu o desenvolvimento da profissão no esquema de trabalho proposto pela organização do trabalho capitalista: trabalho dividido por tarefa, mal remunerado e com excessiva jornada. Ao assim fazê-lo, contraditoriamente ao discurso que transformava as enfermeiras em anjos, dava-lhe a condição de trabalho, parte da divisão do trabalho em saúde, subordinado ao médico, serviço socialmente necessário e portanto, "prática social".

O Século XX trouxe para o trabalho em geral e em saúde particularmente o aprimoramento tecnológico dos instrumentos de trabalho e na Enfermagem este aprimoramento aconteceu na busca pela cientificização do seu saber, na tecnização do cuidado de enfermagem e no domínio dos equipamentos de ponta. Carvalho $^{(15)}$ relata Que em 1923 o Relatório Goldmark trazia a primeira avaliação da Enfermagem como empreendimento social, esclarecendo que no Brasil, o modelo de formação e de prática adotado foi fortemente influenciado por este relatório.

No entanto, o entendimento da enfermagem como um trabalho tem sido retardado em razão dos processos de 'idealização' e 'ideologização' desta área e do positivismo Que tem guiado a prática na saúde e na enfermagem e, conseqüentemente a produção intelectual correspondente a essa área"(12). A penetração da concepção de trabalho na enfermagem só foi possível a partir de dois marcos: o primeiro foi a difusão das idéias de enfermeiras norte americanas na forma das teorias de enfermagem e, o segundo, no Brasil foi a influência do estudo de Donnangelo, em 1979 que muito contribuiu na discussão sobre 'Enfermagem e Estrutura Social ${ }^{(12)}$ realizada por Ivete Oliveira no XXXI Congresso Brasileiro de Enfermagem(CBEn) em 1979. Portanto, ela introduziu a discussão Que colocou a enfermagem sob uma visão históricosocial, numa relação direta com a estrutura social"(12).

Porém, as profissões da área da saúde e pode-se dizer até as profissões de um modo geral, são tomadas no seu estatuto científico de profissão. Isso restringe, em certa medida, o conhecimento de como estas atividades são exercidas em realidades concretas, suas possibilidades e os limites presentes impostos, internos e externos a elas, e as articulações sociais Que se dão entre estas, principalmente Quando se trata de profissões afins como as da área de saúde ${ }^{(9)}$.

Este posicionamento contribui para resgatar o reconhecimento da condição da enfermagem como prática social, contextualizada no mundo do trabalho, parte integrante do processo de trabalho em saúde, sujeita às suas regras, aliada aos seus usuários, na luta contínua por melhores condições de vida.

Ao negar ou escamotear esta condição o corpo da enfermagem colabora para a desvalorização do seu trabalho, tornando sua prática invisível aos olhos das demais profissões e dos usuários Que contribui para a dúvida sobre Qual a parte que lhe cabe (destaque nosso).

O final da década de 70 e a década de 80 foram dedicados pelas organizações da Enfermagem ao resgate deste reconhecimento da enfermagem como pratica social. Vários eventos tiveram o trabalho da enfermagem como foco, tratando-o como uma prática social essencial no processo de assistência à saúde da pessoa. No XXXI CBEn, através da expressão de Carvalho, Castro(16) Que tornou-se clássica, podemos exemplificar esse entendimento, Quando assim trataram a Questão: A prática resume o significado de uma profissão na sociedade. PorQue nela se consubstancia a realização do compromisso social, o Qual, sendo obrigatório e coletivo, garante à profissão sua continuidade no tempo ${ }^{(16)}$. Ou, em palavras mais diretas: ... a prática é Que determina a posição e o status da enfermeira na sociedade... ${ }^{(15)}$.

É interessante ressaltar como essas autoras, naQuele momento já nos chamavam a atenção acerca da condição de permanência da profissão através da história, mediante adaptações contínuas às novas expectativas e necessidades da sociedade, oriundas Que são do desenvolvimento científico e da conseQüente evolução da técnica ${ }^{(18)}$.

Outro exemplo encontramos no XXXIX CBEn, em Salvador/ $\mathrm{Ba}$, no ano de 1987 Que dedicou todo seu temário oficial à discussão sobre o trabalho na enfermagem. Ressaltou o processo e divisão social e técnica desse trabalho, suas condições e inserção no mercado. Significa com isso dizer que a enfermagem foi discutida, como prática social, uma vez Que não é possível se chegar a tal nível e natureza de discussão sem se contextualizar histórica e socialmente a prática em Questão, tratando-a como uma atividade orientada para um determinado fim. Acreditamos que o momento desse congresso constituiu-se como um marco, Que se somou à busca da enfermagem brasileira, antes e depois do mesmo, de sua explicação como uma prática historicamente construída.

$\mathrm{Na}$ academia, teses, livros e artigos também abordaram e continuam abordando esta Questão e argumentam em favor da visão da enfermagem como prática social como uma contribuição libertadora, pois, ao conferir-lhe o estatuto de profissão Que presta serviço à sociedade está contribuindo para a sua perpetuação no mundo do trabalho desta mesma sociedade. Melo ${ }^{(9)}$, Almeida ${ }^{(8,17)}$, Alves $^{(12,18)}$, Carvalho ${ }^{(15,16)}$, Pires ${ }^{(1,19)}$ são exemplo dessa produção acadêmica. A Associação Brasileira de Enfermagem Nacional e instituições como Ministério da Saúde, Organização Panamericana de Saúde e Organização Mundial de Saúde também escreveram sobre a Enfermagem considerando-a como prática social e ao fazêlo colocaram-na como profissão co-responsável pelo processo de prestação de serviços de saúde às pessoas.

\section{ENFERMAGEM COMO PRÁTICA SOCIAL: OS DIAS ATUAIS}

Entender a Enfermagem como uma prática social não significa desprestigiá-la mas, ao contrário, visualizá-la "ombro a ombro" com as demais profissões Que dividem o trabalho de produzir serviços de saúde. Acreditamos mesmo que entender Enfermagem como prática social é admitir a possibilidade de levá-la a sair de sua confortável cápsula de assepsia e neutralidade acadêmica, de poucas trocas e poucas problematizações em relação ao presente, para se dirigir a todos. ... sair das salas de aula e dos ambientes terapêuticos e se ocupar também dos meios de comunicação, se obrigando a negociar, articular, brigar, para se fazer compreender e ser aceita por toda a população"(10).

Como uma profissão tal Qual tantas outras com Quem partilha a responsabilidade de prestar assistência à saúde das pessoas.

Compreender Enfermagem como uma prática social Quer dizer compreendê-la como uma profissão dinâmica, sujeita a transformações permanentes e Que está continuamente incorporando reflexões sobre novos temas, problemas e ações, porque seu princípio ético é o de manter ou restaurar a dignidade do corpo em todos os âmbitos da vida"(10). 
$\mathrm{Na}$ atualidade a Enfermagem tem sido exercida em instituições como um trabalho parcelado, dividido socialmente, onde as tarefas mais elementares são executadas pelos exercentes menos Qualificados e as atividades de comando e supervisão são desenvolvidas por aQueles Que detêm o saber e, portanto, o poder. Essa divisão está consubstanciada em Lei Federal (n. ${ }^{07498 / 86}$ e Dec. N. ${ }^{\circ}$ 94.406/87) onde também se encontra estabelecida a responsabilidade civil dos seus profissionais. As "regras do jogo" estão definidas nosso Código de Ética e o órgão fiscalizador é também o seu tribunal ético.

Essa realidade traduz a tradição capitalista da organização do trabalho, no modelo Taylorista/Fordista. Muitos princípios desta linha administrativa são muito empregados na administração de Enfermagem, sendo necessária uma reflexão mais profunda deste modelo, de forma a contribuir para a superação do trabalho alienado Que expropria o(a) trabalhador(a) de enfermagem do domínio integral do seu processo de trabalho.

Mais que isso, acreditamos que a compreensão da Enfermagem como uma prática social, historicamente construída, nos permitirá ainda ampliar a nossa visão crítica sobre a organização e implementação do processo educacional, estreitando as distâncias entre a academia e os serviços. Esta atitude propiciará o alargamento dos horizontes da pesquisa, criando o ambiente propício para testagem do conhecimento próprio da profissão, ao tempo em Que ampliará a possibilidade de aprofundarmos a nossa capacidade organizativa, na medida em Que nos sentiremos mais solidários com nossos pares e capazes de reconhecer os mecanismos que nos oprime e nos encapsula em nosso próprio umbigo.

Outro campo que se abre ao entender a enfermagem como trabalho, como prática social, é o conhecimento Que precisa ser produzido sobre as táticas de sobrevivência dos trabalhadores da enfermagem. Não são muitos os escritos sobre esta problemática!
Além disso, se nos considerarmos mesmo Gente que cuida de gente, como ensinava Wanda Horta ${ }^{(20)}$, poderemos aprimorar o nosso produto - o cuidado de enfermagem - e poderemos traçar alianças com as pessoas de Quem cuidamos, aprendendo com elas Qual o cuidado Que desejam, como e Quando deve ser feito, trocando com elas experiências Que transformarão a elas e a nós.

Estando a enfermagem assim situada, não há empecilho a Que descreva sua prática, como ciência e/ou arte. Importante é Que amplie as suas possibilidades de desenvolver relações cooperativas resolutivas com seus "consumidores" e com os integrantes da equipe de saúde inclusive seus pares.

Finalizando podemos dizer Que entender a enfermagem como prática social é considerá-la como um trabalho necessário e de interesse da sociedade, inserido no processo de trabalho que produz serviços em saúde, exercido pelos por enfermeiros(as), técnicos(as) e auxiliares de enfermagem e cujo produto final é o cuidado de enfermagem à pessoa no seu processo saúde-doença.

\section{CONSIDERAÇÕES FINAIS}

Pelo exposto, acreditamos ter atendido aos objetivos iniciais a Que nos propusemos, isto é, de trazer uma reflexão sobre o significado da expressão prática social e sobre as implicações da enfermagem ser entendida como tal. Não pretendemos esgotar o assunto, até porQue reconhecemos tratar-se de uma Questão para a Qual as(os) enfermeiras(os) sempre se voltarão, em busca de um melhor entendimento do motivo de sua existência e de sua continuidade no tempo. Importa, pois, Que essas reflexões possam contribuir para uma leitura mais aproximada dessa nossa prática no âmbito de uma sociedade neocapitalista como é a nossa, como fazendo parte de um contexto maior de alianças, de lutas, de compromisso social, tornando-nos sujeitos de nossa história.

\section{REFERÊNCIAS}

I. Ferreira $\mathrm{ABH}$. Novo dicionário da língua portuguesa. $3^{\mathrm{a}}$ ed. Rio de Janeiro: Nova Fronteira; 2004.

2. Abbagnano N. Dicionário de filosofia. São Paulo: Martins Fontes; 1998.

3. Silva B. Dicionário de ciências sociais. Rio de Janeiro: Fundação Getúlio Vargas; 1987.

4. Japiassu H, Marcondes D. Dicionário básico de filosofia. $4^{\mathrm{a}}$. ed. Rio de Janeiro: Zahar; 2006.

5. Althusser L, Badiou A. Materialismo histórico e materialismo dialético. São Paulo: Global Editora; 1979.

6. Lobo Neto FIS, Prado AA, Fontanive DA, Silva PT. Prática social educativa. In: Ministério da Saúde (BR). PROFAE. Formação pedagógica em educação profissional na área de saúde. Brasília: Ministério da Saúde; 2003.

7. Colliere MF. Promover a vida. $3^{\mathrm{a}}$ ed. Coimbra: Lidel; 1999.

8. Almeida MCP. O saber de enfermagem e sua dimensão prática. $2^{\mathrm{a}}$ ed. São Paulo: Cortez; 1989.

9. Melo CMM. Divisão social do trabalho e enfermagem. São Paulo: Cortez; 1986.

10. Lima MJ. O Que é enfermagem? Coleção Primeiros Passos. $4^{a}$ São Paulo: Ed. Brasiliense; 2004.

II. Pires D. Hegemonia médica na saúde e a enfermagem. São Paulo: Cortez; 1989.

12. Alves DB. Produção/reprodução de conhecimentos no trabalho da enfermagem [tese]. Salvador: Universidade Federal da Bahia; 1995.

13. Nightingale F. Notas sobre enfermagem. São Paulo: Cortez; 1989.

14. Albornoz S. O Que é trabalho. São Paulo: Ed Brasiliense; 1995.

15. Carvalho V. A enfermagem de saúde pública como prática social. Rev Ana Nery Enferm 1997; I(1).

16. Carvalho V, Castro I, Barreira I. Barreira. Reflexões sobre a prática da enfermagem. In: Anais do XXXI Congresso Brasileiro de Enfermagem. 1979, Fortaleza (CE), Brasil. Fortaleza: ABEnCE; 1979.

17. Almeida MCP, Rocha SMM. O trabalho de enfermagem. São Paulo: Cortez; 1997.

18. Alves DB. Mercado e condições de trabalho da enfermagem. Salvador: Ed. UFBA; 1987.

19. Pires D. Reestruturação produtiva e trabalho em saúde no Brasil. São Paulo: Confederação Nacional dos Trabalhadores em Seguridade Social; 1998.

20. Horta WA. Processo de enfermagem. São Paulo: EPU; 1979. 